\title{
CD24 expression is a marker for predicting clinical outcome and regulates the epithelial-mesenchymal transition in ovarian cancer via both the Akt and ERK pathways
}

\author{
KIYOKO NAKAMURA, YOSHITO TERAI, AKIKO TANABE, YOSHIHIRO J. ONO, MASAMI HAYASHI, \\ KAZUYA MAEDA, SATOE FUJIWARA, KEISUKE ASHIHARA, MICHIHIKO NAKAMURA, \\ YOSHIMICHI TANAKA, TOMOHITO TANAKA, SATOSHI TSUNETOH, \\ HIROSHI SASAKI and MASAHIDE OHMICHI
}

Department of Obstetrics and Gynecology, Osaka Medical College, Takatsuki-city, Osaka 569-8686, Japan

Received November 24, 2016; Accepted April 3, 2017

DOI: $10.3892 /$ or.2017.5583

\begin{abstract}
The degree of peritoneal dissemination and chemotherapy-resistant tumors is related to the prognosis in patients with advanced-stage ovarian cancer. The epithelialmesenchymal-transition (EMT) is a multifaceted pathological program that endows cancer cells with the ability to invade and disseminate. CD24 is frequently overexpressed in various human cancers and is correlated with a poor prognosis. We herein examined the functions of CD24 in human ovarian cancer cell lines and evaluated how it contributes to the molecular mechanism underlying the regeneration of cancer stem-like cells (CSCs) through the EMT mechanism in ovarian carcinoma. We demonstrated that CD24 was expressed in $70.1 \%$ of primary ovarian carcinoma tissues, which were obtained from 174 patients, and that the expression of CD24 was an independent predictor of survival in patients with ovarian cancer. The expression of CD24 has been found to be correlated with the FIGO stage, presence of peritoneal and lymph node metastasis. CD24 induces the EMT phenomenon, which is involved
\end{abstract}

Correspondence to: Dr Yoshito Terai, Department of Obstetrics and Gynecology, Osaka Medical College, 2-7 Daigaku-machi, Takatsuki, Osaka 569-8686, Japan

E-mail: y-terai@osaka-med.ac.jp

Abbreviations: CD24, cluster of differentiation 24; EMT, epithelialmesenchymal-transition; CSCs, cancer stem-like cells; PI3K-Akt,

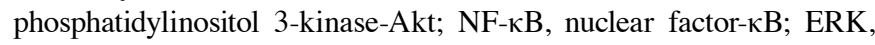
extracellular signal-regulated kinase; MAPK, mitogen-activated protein kinase; RT-PCR, reverse transcription polymerase chain reaction; MTS assay, 3-(4,5-dimethylthiazol-2-yl)-5-(3-carboxymethoxyphenyl)-2-(4sulfophenyl)-2H-tetrazolium assay; MASC, magnetic activated cell sorting; FIGO, International Federation of Gynecology and Obstetrics; SSPCs, serous surface papillary carcinomas

Key words: CD24, ovarian cancer, platinum resistance, epithelialmesenchymal transition, cancer stem-like cells, Snail, Akt, ERK, $\mathrm{NF}-\kappa \mathrm{B}$ in cell invasion, the highly proliferative phenotype, colony formation and which is associated with cisplatin resistance and the properties of CSCs, via the activation of PI3K/Akt, NF- $\mathrm{KB}$ and ERK in Caov-3 cisplatin-resistant cell lines. CD24-positive ovarian carcinomas have been shown to have a greater potential for intra-abdominal tumor cell dissemination in in vivo models. Our findings suggest that CD24 induced the EMT phenomenon in ovarian cancer, and that CD24 amplified cell growth-related intracellular signaling via the PI3K/Akt and MAPK pathways by affecting the EMT signal pathways. We believe that CD24 is a key molecule of metastatic progression in the EMT phenomenon and a promising therapeutic target for advanced ovarian cancer.

\section{Introduction}

Ovarian cancer is the most frequent cause of cancer-related death among all gynecological cancers. Approximately $70 \%$ of patients with ovarian cancer are diagnosed at an advanced stage (1). The degree of peritoneal dissemination and chemotherapy-resistant tumors is related to the prognosis of patients with advanced-stage ovarian cancer. The molecular mechanisms that allow ovarian cancer cells to detach from the primary tumor, invade the peritoneal surface and regrow at this site are not yet well understood. Thus, obtaining a better understanding of the molecular events that contribute to tumor invasion and metastasis is crucial for developing novel treatment strategies for ovarian cancer.

The epithelial-mesenchymal-transition (EMT) is a developmental process in which polarized epithelial cells undergo multiple biochemical changes and assume a mesenchymal phenotype, with increased migratory capacity, invasiveness, resistance to apoptosis and the expression of extracellular matrix components (2-6). The EMT is regulated through the downregulation of the epithelial marker E-cadherin by transcriptional repressors such as Snail and Zeb (5). Importantly, the EMT is involved in cell invasion, resistance to chemotherapy, and the formation of side populations of cancer stem-like cells (CSCs) (7). Such CSCs or tumor initiating cells comprise a sub-population of cancer cells within each 
tumor that have tumorigenic potential in vivo and which are able to recreate the full heterogeneity of the parental tumor (8). However, the molecular mechanism underlying the regeneration of CSCs through EMT has not yet been clarified.

Cluster of differentiation (CD) 24 is a small, heavily glycosylated mucin-like cell surface protein (27-30 amino acids in length), which binds to the membrane via a glycosyl-phosphatidylinositol anchor (9). Under physiological conditions, CD24 was initially identified as a B cell marker (10). Later, it was found to be expressed not only in developing or regenerating tissue, but also in granulocytes, Pre-B cells, keratinocytes and renal tubules (11). CD24 has also been reported to be a ligand for P-selectin, an adhesion receptor on activated endothelial cells and platelets $(12,13)$. These findings suggest that the molecule functionally enhances the metastatic potential of cancer cells. Various studies have identified CD24 as a marker of a poor prognosis in patients with hematological malignancies (14), and various solid tumors, including glioma (15), laryngeal squamous cell carcinoma (16), non-small cell lung cancer (17), breast cancer (18), renal cell carcinoma (19), colorectal cancer (20), bladder carcinoma (21) and epithelial ovarian cancer (22). However, the underlying mechanism has remained elusive. Recent findings have described CD24 as a marker for tumor stem cells in pancreatic and ovarian carcinomas $(23,24)$.

In this study, we demonstrated that CD24 was markedly associated with a more aggressive disease course. The data on CD24 demonstrated that CD24-positive ovarian cancer cells are susceptible to the induction of EMT, and this study provides new knowledge on the function of CD24 in tumor metastasis and its suitability as a therapeutic target in patients with advanced ovarian cancer.

\section{Materials and methods}

Tissue samples. Tissue samples were obtained from 174 Japanese patients who underwent surgical resection for primary ovarian carcinomas at Osaka Medical College between January 2001 and December 2009. All patients underwent a primary staging operation, such as total abdominal hysterectomy, bilateral salpingo-oophorectomy, omentectomy, and/or lymphadenectomy. Furthermore, all patients received 6-course conventional TC (paclitaxel and carboplatin) therapies as the adjuvant chemotherapy. The median follow-up duration was 29.2 months (range, 2-122 months). The institutional review board approved this study (no. 0156) and informed consent was obtained from all of the patients. We performed a tissue microarray of the assembly of 5-mm cores retrieved from microscopically selected representative tissues of the primary tumors. The specimens were fixed in $10 \%$ formalin and embedded in paraffin. Serial sections cut out from paraffin-embedded blocks were used for routine histopathology. A 4- $\mu \mathrm{m}$ section was cut from a tissue microarray block and was immunohistochemically analyzed to detect the expression of CD24.

Immunohistochemistry. Tumor samples were formalin-fixed and embedded in paraffin. Deparaffinized and rehydrated sections $(4-\mu \mathrm{m})$ were autoclaved in $0.01 \mathrm{~mol} / 1$ citrate buffer (pH 6.0) for $15 \mathrm{~min}$ at $121^{\circ} \mathrm{C}$ for antigen retrieval. Endogenous peroxidase activity was blocked with $0.3 \%$ solution hydrogen peroxidase in methanol for $30 \mathrm{~min}$. Tumor sections were incubated at $4{ }^{\circ} \mathrm{C}$ for $12 \mathrm{~h}$ with a CD24-specific antibody (1:50 dilution; Thermo Fisher Scientific, Yokohama, Japan). The sections were washed with $1 \mathrm{X}$ phosphate-buffered saline (PBS) and incubated with Histofine Simple Stain MAX PO (Multi; Nichirei) for $30 \mathrm{~min}$ at room temperature. Finally, the sections were washed with $1 \mathrm{X}$ PBS and the signals were visualized by incubation with $\mathrm{H}_{2} \mathrm{O}_{2}$ /diaminobenzidine substrate solution for $5 \mathrm{~min}$. The sections were counterstained with hematoxylin prior to dehydration and mounting. The evaluation of the immunohistochemical data was performed by two independent pathologists who were blinded to the clinicopathological data. For the immunohistochemistry score, the expression levels of CD24 were assessed using a semiquantitative system based on the staining intensity ( 0 , negative; $1+$, weak; $2+$, moderate; $3+$, strong) and the percentage of cells positively stained cells $(0-100 \%)$, with the positive expression of CD24 defined as $\geq 50 \%$ of tumor cells having a membranous or cytoplasmic staining intensity of $\geq 2+$, as described by Kim et al (25). Scoring was performed three times per slide for three distinct fields, and the three scores were averaged.

Reagents/antibodies. Cisplatin was also purchased from SigmaAldrich (St. Louis, MO, USA). The anti-phospho-Akt (ser473), anti-Akt antibodies, anti-phospho-ERK (Thr202/Tyr204), anti-ERK antibodies, anti-phospho-NF- $\mathrm{BB}$ (Ser536), and anti$\mathrm{NF}-\kappa \mathrm{B}$ antibodies purchased from Cell Signaling Technology (Beverly, MA, USA).

Cell culture. One human ovarian mucinous adenocarcinoma cancer cell line, Caov-3, which was obtained from the American Type Culture Collection (Rockville, MD, USA), was grown in phenol DMEM containing $10 \%$ dextran-coated, charcoal-treated fetal calf serum in a humidified atmosphere of $5 \% \mathrm{CO}_{2}$ with $95 \%$ air at $37^{\circ} \mathrm{C}$.

The expression plasmids and cDNA transfection. We purchased pEZ-M02-CD24 (Gene Copoeia, Rockville, MD, USA) which used Homo sapiens CD24 signal transducer mRNA. For the transfection of each sample, oligomer-Lipofectamine plus complexes were prepared as follows: $4.0 \mu \mathrm{g}$ of cDNA oligomer were diluted in $250 \mu \mathrm{l}$ of Opti-MEM (Invitrogen, CA, USA). The oligomer-Lipofectamine plus complexes were added to each of the wells, which contained cells and medium; gentle mixing was then performed by rocking the plate back and forth. The cells were incubated at $37^{\circ} \mathrm{C}$ in a $\mathrm{CO}_{2}$ incubator for $18 \mathrm{~h}$. The cells were then prepared for each assay.

CD24 mRNA depletion by the plasmid transfection of siRNA. We purchased the Trilencer-27 siRNA plasmid for human CD24 (OriGene, Rockville, MD, USA), as well as scrambled sequence negative control plasmid (OriGene). Caov-3 cells were transfected using the CD24 siRNA Lipofectin method, according to the manufacturer's protocol, which was the same method that was used for the expression of CD24.

The reverse transcription polymerase chain reaction $(R T-P C R)$. Caov-3 cells were treated with PBS, TGF- $\beta$ for $24 \mathrm{~h}$. Total RNA was isolated from cells using an RNeasy 
Protect Mini kit (Qiagen) according to the manufacturer's protocol. The Super Script II Reverse Transcriptase kit (Invitrogen) was used to synthesize cDNA. Polymerase chain reactions were performed with a Platinum PCR SuperMix (Invitrogen) system according to the manufacturer's protocol. The following primers were used for the PCR: CD24 forward, 5'-ACCCACGCAGATTTATTCCA-3'; reverse, 5'-ACCACGA AGAGACTGGCTGT-3'. Snail forward, 5'-GCCTTCAACTG CAAATACTGC-3'; reverse, 5'-CTTCTTGACATCTGAGTG GGTC-3'. Ecad forward, 5'-GGTGGGTGACTACAAAATC AATCTC-3'; reverse, 5'-GGGGCAGTAAGGGCTCTTT-3'. $\beta$-actin forward, 5'-GAATTCATGTTTGAGACCTTCAA-3'; reverse, 5'-CCGGATCCATCTCTTGCTCGAAGTCCA-3'. The expression levels of $\beta$-actin were assessed as an internal control in all reactions.

Flow cytometry. The cultures from the Caov-3 cell lines were washed with PBS. For some experiments, single cells dissociated from tumor spheres were analyzed by the following method. One million trysinized cells were incubated with 7-amino-actinomycin D (BD Biosciences, NJ, USA) only or 7-amino-actinomycin D and a mouse anti-human monoclonal antibody of CD24-FITC (BD Biosciences) with stain buffer (BD Pharmingen $^{\mathrm{TM}}$ ) for $20 \mathrm{~min}$ at room temperature in the dark. After washing, the cells were analyzed using a BD FACS $\mathrm{Aria}^{\mathrm{TM}}$. The fluorescence intensity was analyzed using the BD FACS Diva software program (BD Biosciences).

Magnetic activated cell sorting (MACS). The CD24-positive/ CD24-negative Caov-3 cells were obtained using the MACS kit according to the manufacturer's instructions (Miltenyi Biotec, Nordrhein-Westfalen, Germany). Briefly, total populations of adherent cells were enzymatically dissociated into a single cell suspension and counted to confirm the quantity of the whole cells. The cells were incubated with $40 \mu \mathrm{l}$ buffer per $10^{7}$ total cells, which were directly conjugated to $10 \mu \mathrm{l}$ of CD24 Biotin at $4^{\circ} \mathrm{C}$ for $15 \mathrm{~min}$. After washing, the cells were incubated with $80 \mu \mathrm{l}$ buffer directly conjugated to $20 \mu \mathrm{l}$ of Anti-Biotin MicroBeads at $4^{\circ} \mathrm{C}$ for $15 \mathrm{~min}$. Subsequently, the suspended cells were added to a MACS column that was placed in the magnetic field of a MACS separator (Miltenyi Biotech). The labeled CD24-positive cells were retained on the column and the unlabeled cells were eluted; when the column was removed from the magnetic field, the magnetically retained CD24-positive cells were collected as positively selected cells for further investigation. We also confirmed the expression of CD24 mRNA in CD24-positive and CD24-negative Caov-3 cells using conventional PCR. All experiments were performed three times.

The soft agar assay. The Caov-3 cells sorted CD24-positive/ CD24-negative by MACS. A 6-well culture plate was coated with $2 \mathrm{ml}$ of bottom agar mixture (DMEM/F12 with $10 \% \mathrm{FBS}$, $0.6 \%$ agar). After the bottom layer solidified, $2 \mathrm{ml}$ top agarmedium mixture (DMEM/F12 with $10 \%$ FBS, $0.3 \%$ agar) containing $2 \times 10^{4} \mathrm{CD} 24$-positive or CD24-negative cells was added, and the plate was incubated at $37^{\circ} \mathrm{C}$ for 4 weeks. The medium was replenished every 3 days. The plate was stained with $0.5 \%$ crystal violet, and the colonies with a diameter of $>40 \mu \mathrm{m}$ were counted.
The cell proliferation assay. CD24-positive/CD24-negative Caov-3 cells were obtained using a MACS kit. CD24-positive and CD24-negative cells $\left(1 \times 10^{5}\right.$ cells/well) were seeded in triplicate in a 6-well plate with serum-free DMEM to achieve cellular starvation. After $24 \mathrm{~h}$, the medium was replaced with $100 \mathrm{ml}$ complete growth medium and incubated for 1 more week. The cell numbers were counted manually with an optical microscope after 1,3,5 and 7 days. This experiment was carried out in quadruplicate.

The cell invasion assays. Cell invasion was assessed using 24-well-Transwell chambers (Corning, NY, USA) with a pore size of $8 \mu \mathrm{m}$ (Kurabo, Osaka, Japan). Transwell upper chambers were pre-coated with $5 \mu \mathrm{g} / \mathrm{chamber}$ of solubilized basement membrane (Matrigel; BD Biosciences). Forty percent fibronectin was added to the bottom chamber. Ovarian cancer cells $\left(2.5 \times 10^{5}\right.$ per chamber) were seeded in the serum-containing media in the upper well of the Transwell chambers and incubated for $16 \mathrm{~h}$ at $37^{\circ} \mathrm{C}$ in $5 \% \mathrm{CO}_{2}$. The non-invasive cells in the lower chamber (below the filter surface) were fixed in $100 \%$ methanol after $3.7 \%$ formaldehyde, stained with Giemsa staining solution, and counted under a microscope (x40 magnification). Cells from at least five fields were counted per chamber.

The chemotherapeutic sensitivity assay. Cells cultured in $10 \%$ growth medium were seeded in 96 -well plates at a density of $2 \times 10^{4}$ cells per well. After $16 \mathrm{~h}$ of starvation, the cells were incubated for $48 \mathrm{~h}$ before being exposed to $0,10,50$ or $100 \mu \mathrm{M}$ cisplatin, which was purchased from Sigma-Aldrich. Then, CellTiter 96 AQueous (MTS) One Solution reagent (Promega, Tokyo, Japan) was added to each well, and the absorbance was recorded at $490 \mathrm{~nm}$ using a Corona SH-1000 lab absorbance microplate reader (Corona Electric Co. Inc., Ibaraki, Japan). The cell numbers were then calculated using a standard curve of the correlation of absorbance with the cell number counted under a microscope. All of the experiments were carried out in quadruplicate, and cell viability was expressed as the ratio of the number of viable cells with cisplatin treatment to that of untreated cells.

Western blotting. The cells were serum-starved and stimulated with PBS or $10 \mathrm{ng} / \mathrm{ml}$ TGF- $\beta$ for $10 \mathrm{~min}$. The cells were then washed three times in ice-cold PBS and lysed using Pierce RIPA buffer (Thermo Fisher Scientific) and the cytoplasmic and nuclear fractions were separated using a Nuclear Extract kit (Active Motif Carlsbad, CA, USA). To detect all of the proteins, equal amounts of cytoplasmic proteins were separated by SDS-polyacrylamide gel electrophoresis and transferred to nitrocellulose membranes. Blocking was performed in $10 \%$ bovine serum albumin in $1 \mathrm{X}$ Tris-buffered saline. Western blotting was performed with the primary antibody of CD24 (1:100 dilution), phosphorylated Akt (1:1,000 dilution), Akt (1:1,000 dilution), phosphorylated ERK (1:1,000 dilution), ERK (1:1,000 dilution), phosphorylated NF- $\kappa$ B (1:1,000 dilution), and NF- $\kappa \mathrm{B}$ (1:1,000 dilution) overnight at $4^{\circ} \mathrm{C}$. Finally, the bands were visualized using enhanced chemiluminescence (ECL Plus, GE Healthcare Life Sciences, Pittsburgh, PA, USA). All of the western blots were checked for equal protein loading using Ponceau staining. 
The intraperitoneal xenograft model. Female 5-week-old athymic nude mice (BALB/c Slc-nu/nu) were purchased from Japan SLC and maintained in accordance with the institutional guidelines of Osaka Medical College. All of the animal studies were carried out according to approved experimental protocols. To assess tumorigenicity, $80 \times 10^{4}$ purified CD24-positive and CD24-negative cells were suspended in $1 \mathrm{ml}$ PBS and were then intraperitoneally injected into each of the 10 female nude mice (5-week-old). The body weight and abdominal circumference were measured weekly. On the 50th day after the initiation of treatment, all of the mice were sacrificed, and the presence of macroscopic disease and the ascites volumes and organ weight were examined. Dissemination tumors were resected, fixed in formalin and paraffin sections were made for hematoxylin and eosin staining.

Statistical analysis. The statistical analyses in this study were performed using the JMP software program (SAS Institute, Japan). Fisher's exact probably test was used to evaluate the correlations between the immunohistochemical and clinical data. The endpoints were progression-free survival (defined as the time from the first day of chemotherapy until disease progression, based on the findings of imaging studies) and overall survival (defined as the time from the first day of chemotherapy to death from any cause). The univariate analyses of the histology, progression-free survival and overall survival were determined according to the Kaplan-Meier method using the log-rank test and the Cox proportional hazards model, respectively. Differences with p-values of $<0.05$ were considered to indicate statistical significance.

\section{Results}

The expression of $\mathrm{CD} 24$ in ovarian cancer patients. The data that we investigated included the patients' age, histology, International Federation of Gynecology and Obstetrics (FIGO) stage, peritoneal cytology, the presence of lymph node metastasis, the presence of peritoneal metastasis and the outcome, as shown in Table I. The 174 epithelial ovarian cancers included serous adenocarcinomas $(\mathrm{n}=48)$, mucinous adenocarcinomas $(n=21)$, endometrioid adenocarcinomas $(n=32)$, clear cell adenocarcinomas $(n=32)$, serous surface papillary carcinomas (SSPCs; $n=26)$ and others $(n=15)$. The disease stages of the 174 investigated patients were classified as follows: stage I, $n=56$; stage II, $n=14$; stage III, $n=85$ and stage IV, $\mathrm{n}=19$. Representative examples of immunohistochemical staining with anti-CD24 antibody are shown in Fig. 1. CD24 was expressed in a significantly higher percentage of patients with serous adenocarcinoma (87.5\%) and SSPCs (84.6\%) than among patients with other histological subtypes $(\mathrm{p}<0.01)$. In the analysis of the FIGO stage, CD24 was expressed in 53.6, 78.6, 77.7 and $79.0 \%$ of the patients with stage I, II, III and IV disease, respectively. CD24 was expressed in 70.8\% of the patients with positive peritoneal cytology and $68.1 \%$ of the patients with negative peritoneal cytology. The expression of CD24 was observed in $78.7 \%$ of the patients with peritoneal metastasis, in comparison to $60.0 \%$ of the patients without peritoneal metastasis. The expression of CD24 was observed in $87.9 \%$ of the patients with lymph node metastasis, in comparison to $60.7 \%$ of the patients without lymph node
Table I. The immunohistochemistry results.

\begin{tabular}{|c|c|c|c|}
\hline \multirow[b]{2}{*}{ Variables } & \multicolumn{2}{|c|}{ CD24 } & \multirow[b]{2}{*}{ P-value } \\
\hline & Negative & Positive & \\
\hline Age, years & & & 0.18 \\
\hline$<50$ & $18(37.5)$ & $30(62.5)$ & \\
\hline$\geq 50$ & $34(27.0)$ & $92(73.0)$ & \\
\hline Histology & & & $<0.01$ \\
\hline $\begin{array}{l}\text { Serous } \\
\text { adenocarcinoma }\end{array}$ & $6(12.5)$ & $42(87.5)$ & \\
\hline $\begin{array}{l}\text { Mucinous } \\
\text { adenocarcinoma }\end{array}$ & $13(61.9)$ & $8(38.1)$ & \\
\hline $\begin{array}{l}\text { Clear cell } \\
\text { adenocarcinoma }\end{array}$ & $12(37.5)$ & $20(62.5)$ & \\
\hline $\begin{array}{l}\text { Endometrioid } \\
\text { adenocarcinoma }\end{array}$ & $13(40.6)$ & $19(59.4)$ & \\
\hline SSPCs & $4(15.4)$ & $22(84.6)$ & \\
\hline Others & $4(26.6)$ & $11(73.4)$ & \\
\hline Stage & & & $<0.001$ \\
\hline I & $26(46.4)$ & $30(53.6)$ & \\
\hline II & $3(21.4)$ & $11(78.6)$ & \\
\hline III & $19(22.3)$ & $66(77.7)$ & \\
\hline IV & $4(21.0)$ & $15(79.0)$ & \\
\hline Peritoneal cytology & & & 0.75 \\
\hline Positive & $38(29.2)$ & $92(70.8)$ & \\
\hline Negative & $14(31.8)$ & $30(68.1)$ & \\
\hline Dissemination & & & $<0.01$ \\
\hline Positive & $20(21.3)$ & $74(78.7)$ & \\
\hline Negative & $32(40.0)$ & $48(60.0)$ & \\
\hline Lymph node metastasis & & & $<0.01$ \\
\hline Positive & $4(12.1)$ & $29(87.9)$ & \\
\hline Negative & $35(39.3)$ & $54(60.7)$ & \\
\hline Recurrence & & & $<0.01$ \\
\hline Positive & $18(19.1)$ & $76(80.9)$ & \\
\hline Negative & $34(42.5)$ & $46(57.5)$ & \\
\hline Died or survived & & & 0.02 \\
\hline Died & 11 (18.6) & $48(81.4)$ & \\
\hline Survived & $41(35.7)$ & $74(64.3)$ & \\
\hline
\end{tabular}

metastasis. Significant associations were observed between the CD24 expression rate and the FIGO stage $(p<0.01)$, and the presence of peritoneal $(\mathrm{p}<0.01)$ and lymph node metastasis $(\mathrm{p}<0.01)$.

The prognostic impact of the CD24 expression status in patients with ovarian carcinoma. The CD24 expression status was investigated in relation to patient survival. All patients underwent a primary staging operation such as total abdominal hysterectomy, bilateral salpingo-oophorectomy, omentectomy, and/or lymphadenectomy. Furthermore, all patients received 
A

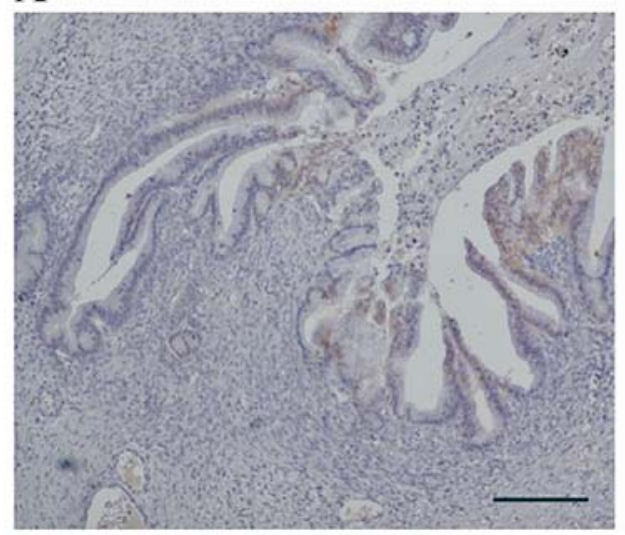

B

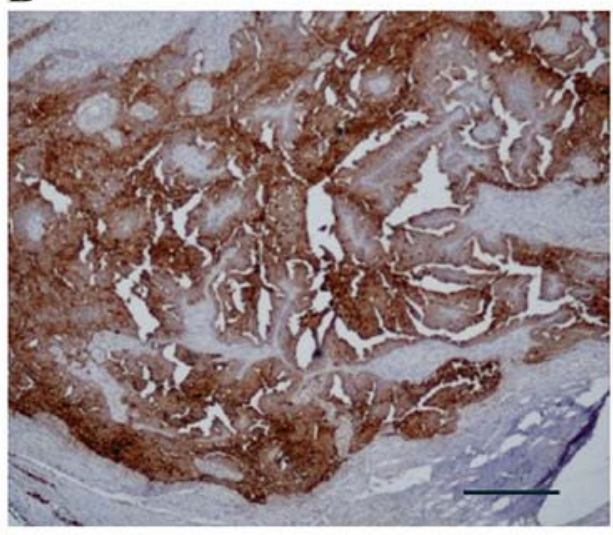

Figure 1. Sequential sections immunohistochemically stained with CD24 in ovarian carcinoma. A representative example of CD24-negative stage 2C serous adenocarcinoma (A), and CD24-positive stage 3C serous adenocarcinoma (B). (A and B) x40 original magnification. The scale bars represent $100 \mu \mathrm{m}$.

A

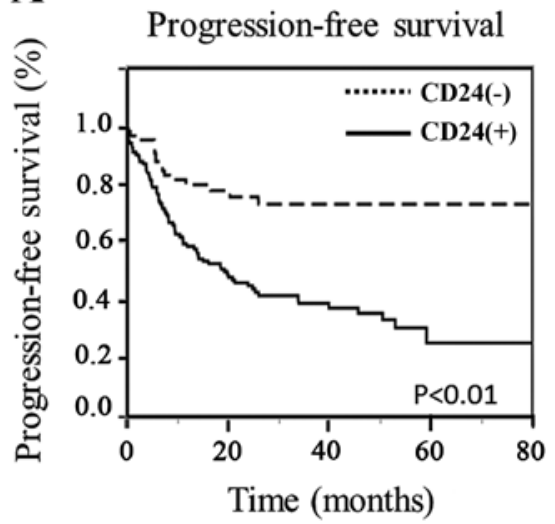

B

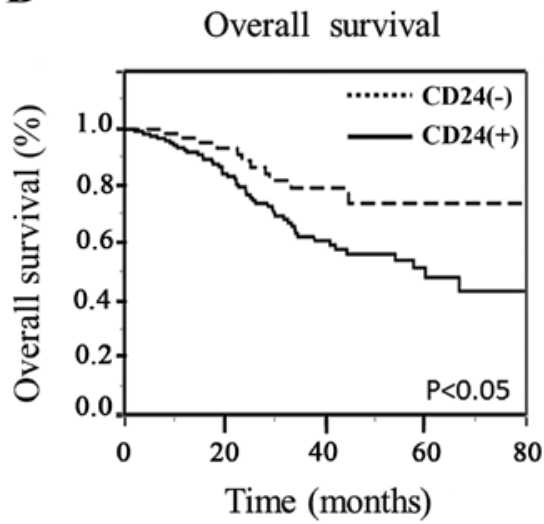

Figure 2. The survival curves generated using the Kaplan-Meier method in 174 ovarian cancer patients. The progression-free survival (A) and overall survival (B) of the patients were stratified according to the expression of CD24. P-values were calculated using the log-rank test.

6-course conventional TC (paclitaxel and carboplatin) therapies as the adjuvant chemotherapy. The median follow-up duration was 29.2 months (range, 2-122 months). During the follow-up period, 94 of 174 patients (54\%) had recurrent disease (18 from the CD24-negative group and 76 from the CD24-positive group), and 59 of 174 patients (33.9\%) died (11 from the CD24-negative group and 48 from the CD24positive group), as shown in Table I. As shown in Fig. 2, progression-free and overall survival were stratified according to the CD24 expression status using the Kaplan-Meier method with the log-rank test. The CD24 expression status was found to be significantly associated with both the progression-free survival $(\mathrm{p}<0.01)$ and overall survival $(\mathrm{p}<0.05)$.

TGF- $\beta$ stimulates EMT and CD24 expression. To study the EMT mechanism, we cultured cisplatin-resistant ovarian cancer cell lines (Caov-3 cells) in medium containing TGF- $\beta$. TGF- $\beta$ is a major inducer of EMT during embryonic development, the pathogenesis of fibrotic disorders and cancer progression (26-28). It was first described as an inducer of the EMT in normal mammary epithelial cells (29). We examined whether there was a correlation between the EMT mechanism induced by TGF- $\beta$ and the expression of CD24 in Caov-3 cells. The data from a quantitative PCR indicated that the expression of Snail was increased with TGF- $\beta$ in the cultured medium, and that the expression of E-cadherin was decreased with TGF- $\beta$ in the cultured medium, as shown in Fig. 3A. The expression of CD24 was also increased with TGF- $\beta$ in the cultured medium. These findings suggest that TGF- $\beta$ stimulates not only the EMT phenotypes but also the expression of CD24 in Caov-3 cells.

Hypoxia stimulates EMT and CD24 expression. A hypoxic microenvironment, which is common to cancer cells emerges as an important factor in the induction of a pathological EMT, which is a key link in cancer progression (30). We examined whether there is a correlation between the EMT mechanism induced by hypoxia and the expression of CD24 in Caov- 3 cells. We cultured Caov-3 cells under the condition of $1 \%$ hypoxia for 12 h. As shown in Fig. 3B, the data from quantitative PCR indicated that the expression of Snail was increased, and that the expression of E-cadherin was decreased under $1 \%$ hypoxia in comparison to normoxia. The expression of CD24 was also increased under $1 \%$ hypoxia (Fig. 3B). Next, we performed flow cytometry to examine whether the $\mathrm{CD} 24$ fraction of the Caov-3 cells was changed under the condition of $1 \%$ hypoxia. 
A

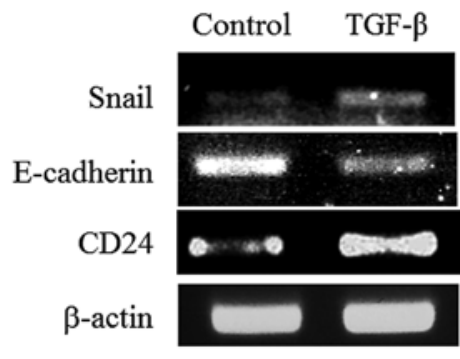

E-cadherin

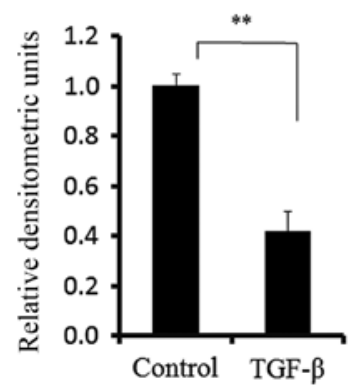

B

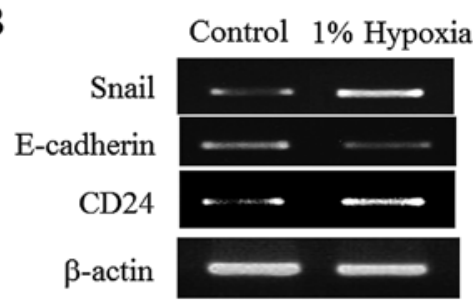

E-cadherin

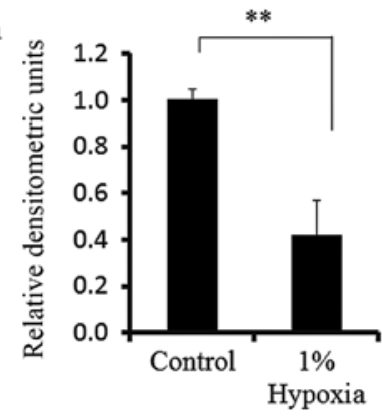

Snail

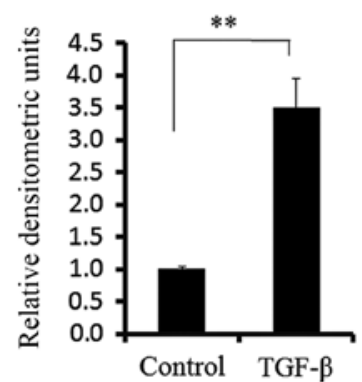

CD24

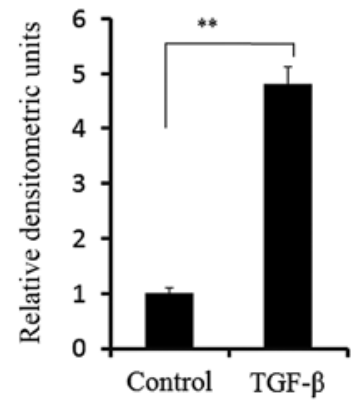

Snail

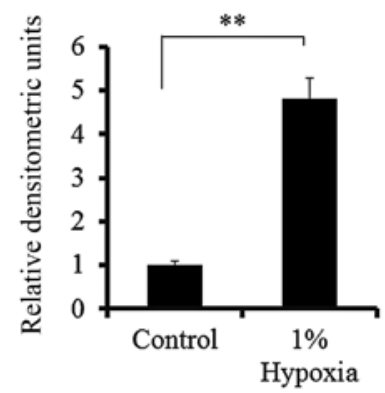

$\mathrm{CD} 24$

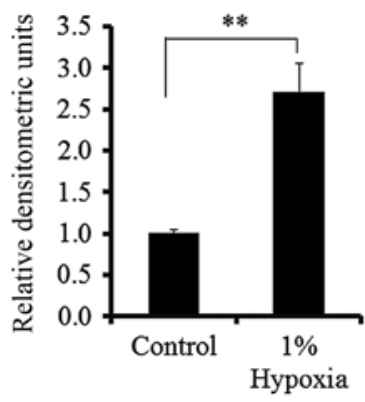

Figure 3. The correlation between the EMT mechanism induced by TGF- $\beta$ and $1 \%$ hypoxia. (A) TGF- $\beta$ enhanced the expression of Snail or CD24, and reduced the expression of E-cadherin in Caov-3 cells. (B) A condition of $1 \%$ hypoxia for $12 \mathrm{~h}$ enhanced the expression of Snail or CD24, and reduced the expression of E-cadherin in Caov-3 cells. ${ }^{* *} \mathrm{p}<0.01$.

The CD24 fraction under normoxia and 1\% hypoxia was 52.9 and $72.9 \%$, respectively (data not shown). These findings suggest that hypoxic conditions stimulate not only the EMT phenotypes but also the expression of CD24 in Caov-3 cells.

CD24 induces EMT in ovarian cancer cells. We examined whether cells with the overexpression of CD24 induced the EMT mechanism in Caov-3 cells. As shown in Fig. 4A, the data from a quantitative PCR indicated that the expression of Snail was increased, and that the expression of E-cadherin was decreased in the CD24-overexpressing cells in comparison to control cells. We confirmed that CD24 directly induced the EMT phenotypes in Caov-3 cells and that the CD24-positive Caov- 3 cells showed the acquisition of spindle cell morphology, as shown in Fig. 4B.
CD24-positive cells have enhanced proliferation, a highly invasive phenotype, colony formation and are associated with cisplatin resistance in ovarian cancer cells. Several groups have reported that the EMT contributes to the properties of cancer stem cells $(31,32)$. We examined whether CD24 could increase the colony-forming activity of CD24-positive Caov-3 cells. As shown in Fig. 5, after 28 days of culture, CD24-positive Caov-3 cells formed more colonies than CD-negative Caov-3 cells.

To obtain further insight into the biological relevance of CD24-positive cells, we analyzed their effect on the proliferative activity of Caov-3 cells by manual cell counting. As shown in Fig. 6A, CD24-positive Caov-3 cells showed an enhanced proliferation rate after 7 days of culture in comparison to CD24-negative Caov-3 cells. We next examined 
A

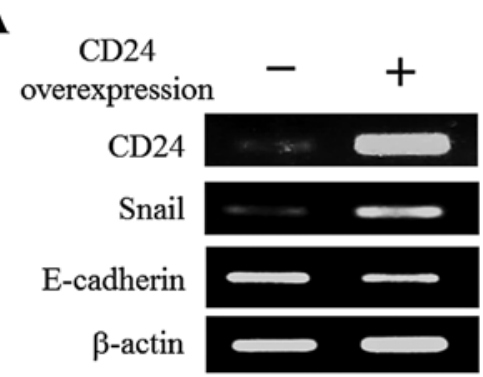

CD24

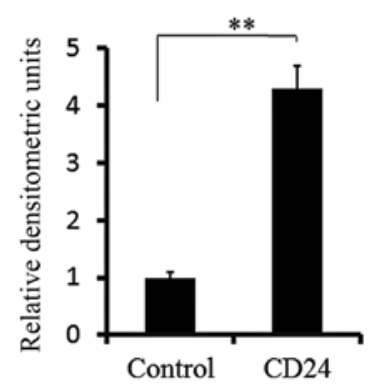

B

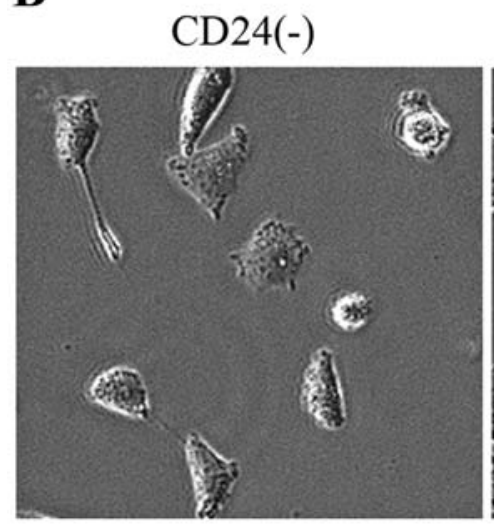

Snail

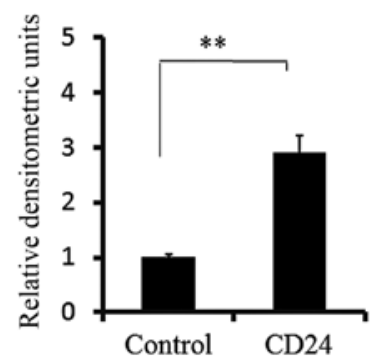

E-cadherin

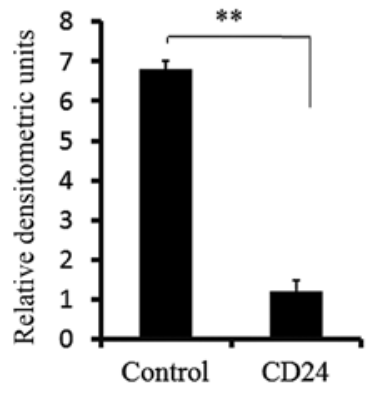

Figure 4. CD24 induces the EMT mechanism in ovarian cancer cells. (A) CD24-overexpressing cells enhanced the expression of Snail, and reduced the expression of E-cadherin. ${ }^{* *}$ p $<0.01$ (B) The CD24-positive Caov-3 cells showed the acquisition of spindle cell morphology compared with the CD24-negative Caov-3 cells.
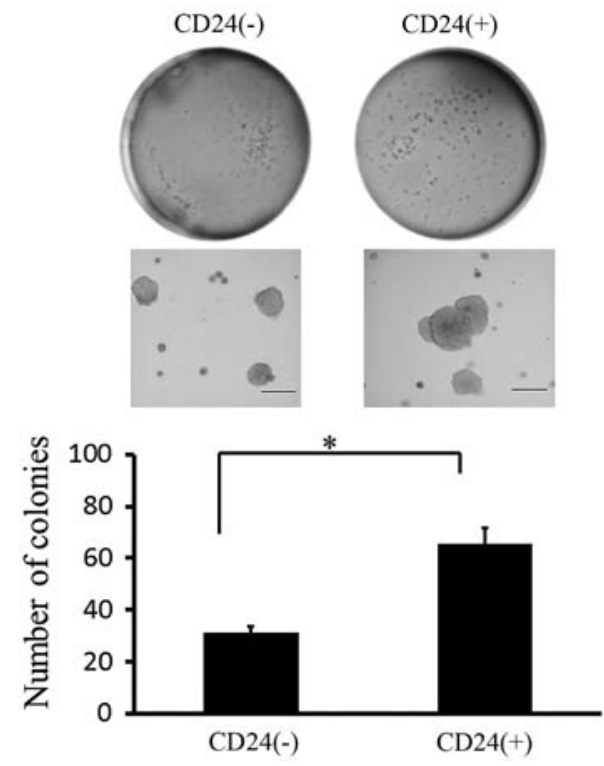

Figure 5. CD24-positive cells show enhanced colony formation. After 28 days of culture, CD24-positive Caov-3 cells formed more colonies than the CD24-negative Caov-3 cells. the correlation between the expression of $\mathrm{CD} 24$ and the invasiveness of ovarian cancer. CD24-overexpressing cells showed 7.5-fold greater invasion in comparison to the control cells $(\mathrm{p}<0.01)$. Moreover, CD24 siRNA-transfected cells significantly inhibited the invasive activity of ovarian cancer (Fig. 6B).

To clarify whether the CD24-positive cells were more resistant to cisplatin than CD24-negative cells, we divided the Caov-3 cells into CD24-positive and CD24-negative fractions using MACS and performed an MTS assay with various concentrations of cisplatin. As shown in Fig. 7A, the CD24-positive Caov-3 cells were more resistant to cisplatin treatment than the CD24-negative Caov-3 cells. We confirmed that the CD24-overexpressing cells were also more resistant to cisplatin treatment than the CD24 siRNA-transfected cells (Fig. 7B).

The long-term differentiation potential of CD24-positive cells. During long-term culture, in addition to increasing their cell mass, CSCs also undergo asymmetric division to generate a cell population with heterogeneous phenotypes 
A

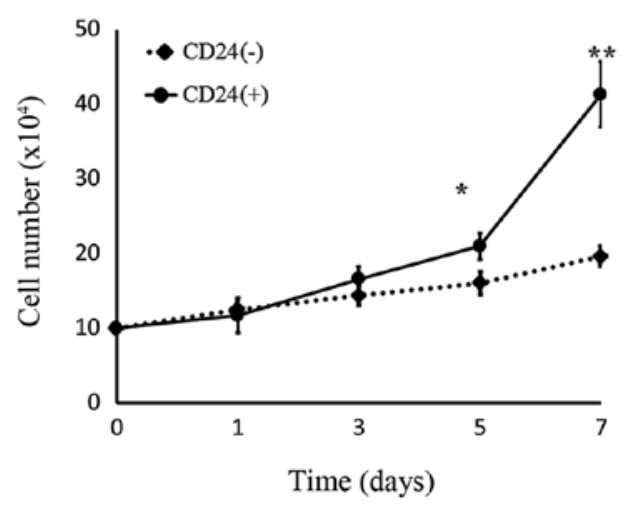

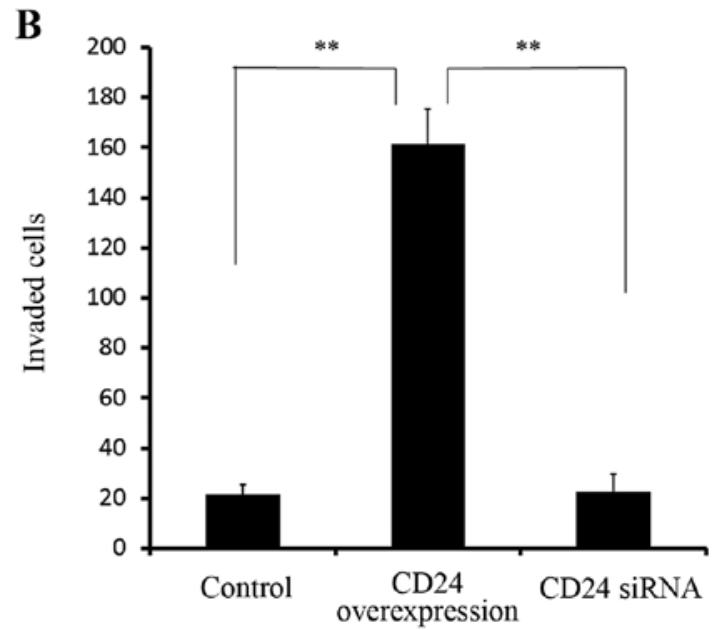

Figure 6. CD24-positive cells show enhanced proliferation and a highly invasive phenotype in Caov-3 cells. (A) After 7 days of culture, CD24-positive Caov-3 cells showed an enhanced proliferation rate in comparison to CD24-negative Caov-3 cells. (B) The correlation between the expression of CD24 and the invasiveness of ovarian cancer as determined by an invasion assay. ${ }^{*} \mathrm{p}<0.05 ;{ }^{* *} \mathrm{p}<0.01$.

A

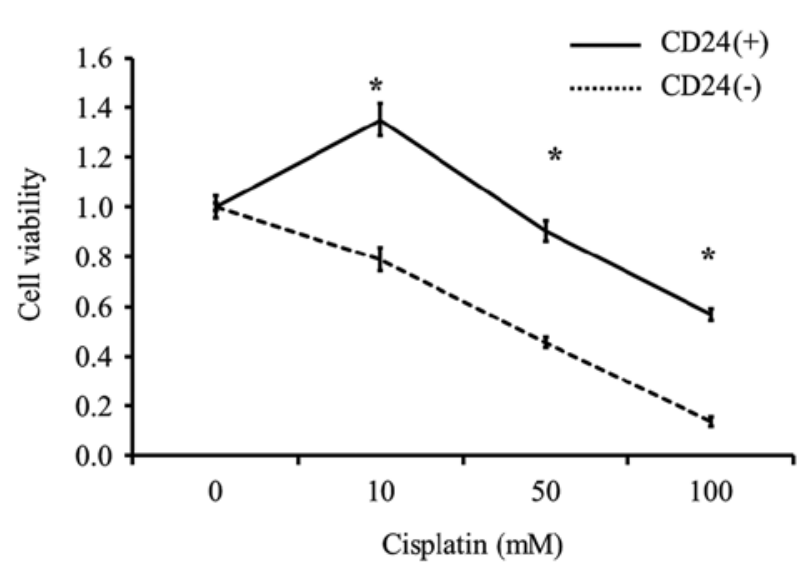

B

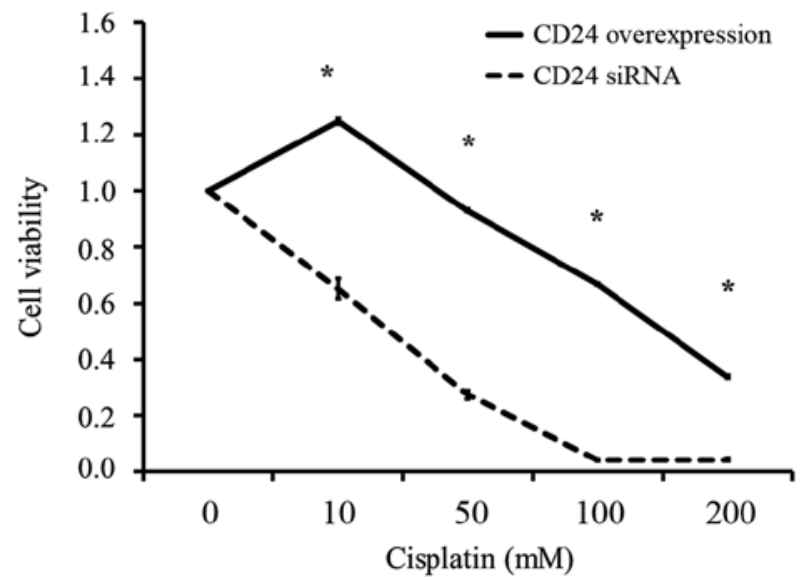

Figure 7. CD24-positive cells associated with cisplatin resistance in Caov-3 cells. (A) CD24-positive Caov-3 cells were found to be more resistant to cisplatin treatment than CD24-negative cells by an MTS assay. (B) CD24-overexpressing cells were also found to be more resistant to cisplatin treatment than the CD24 siRNA-transfected cells by the MTS assay. ${ }^{\mathrm{p}}<0.05 ;{ }^{* *} \mathrm{p}<0.01$.

and low tumorigenicity (33). We divided the Caov-3 cells into CD24-positive and CD24-negative fractions using MACS, and examined whether the CD24-positive and negative fractions of Caov-3 cells changed in the fraction after 7 days of culture by flow cytometry, as shown in Fig. 8. After 7 days of culture, $66.5 \%$ of the CD24-positive fractions cells were CD24-positive and $33.5 \%$ were CD24-negative. Interestingly, after 7 days of culture, $87.4 \%$ of the CD24-negative fractions cells were CD24-negative, while only $12.6 \%$ were CD24positive. These results suggest that CD24-positive cells show self-renewal potential and cell differentiation potential after prolonged culture.

CD24 differentially promotes the activation of the Akt and ERK pathway via the TGF- $\beta$ signaling cascade in ovarian cancer cell lines. TGF- $\beta$ is major inducer of the EMT during embryonic development, the pathogenesis of fibrotic disorders and cancer progression (26-28). It was first described as an inducer of the EMT in normal mammary epithelial cells (29). As the TGF- $\beta$ signaling pathway is located upstream of both the PI3k/Akt and MAPK pathways, we anticipated that there would be a connection between CD24 and the TGF- $\beta$ signaling pathway. To determine whether CD24 has any effect on the TGF- $\beta$ signaling pathway, the Akt phosphorylation status and the ERK phosphorylation status were assessed by western blotting. As shown in Fig. 9, both Akt and ERK were significantly more phosphorylated in Caov-3 cells that were treated with TGF- $\beta$ than in Caov- 3 cells that were not treated with TGF- $\beta$. The phosphorylation of both Akt and ERK was significantly enhanced in CD24-overexpressing Caov-3 cells in comparison to the scrambled transfected Caov-3 cells. Moreover, we examined whether CD24 had any effect on the $\mathrm{NF}-\kappa \mathrm{B}$ phosphorylation status. $\mathrm{NF}-\kappa \mathrm{B}$ was significantly more phosphorylated in Caov-3 cells that were treated with TGF- $\beta$, and was significantly enhanced in CD24-overexpressing Caov-3 cells in comparison to control cells (data not shown). 

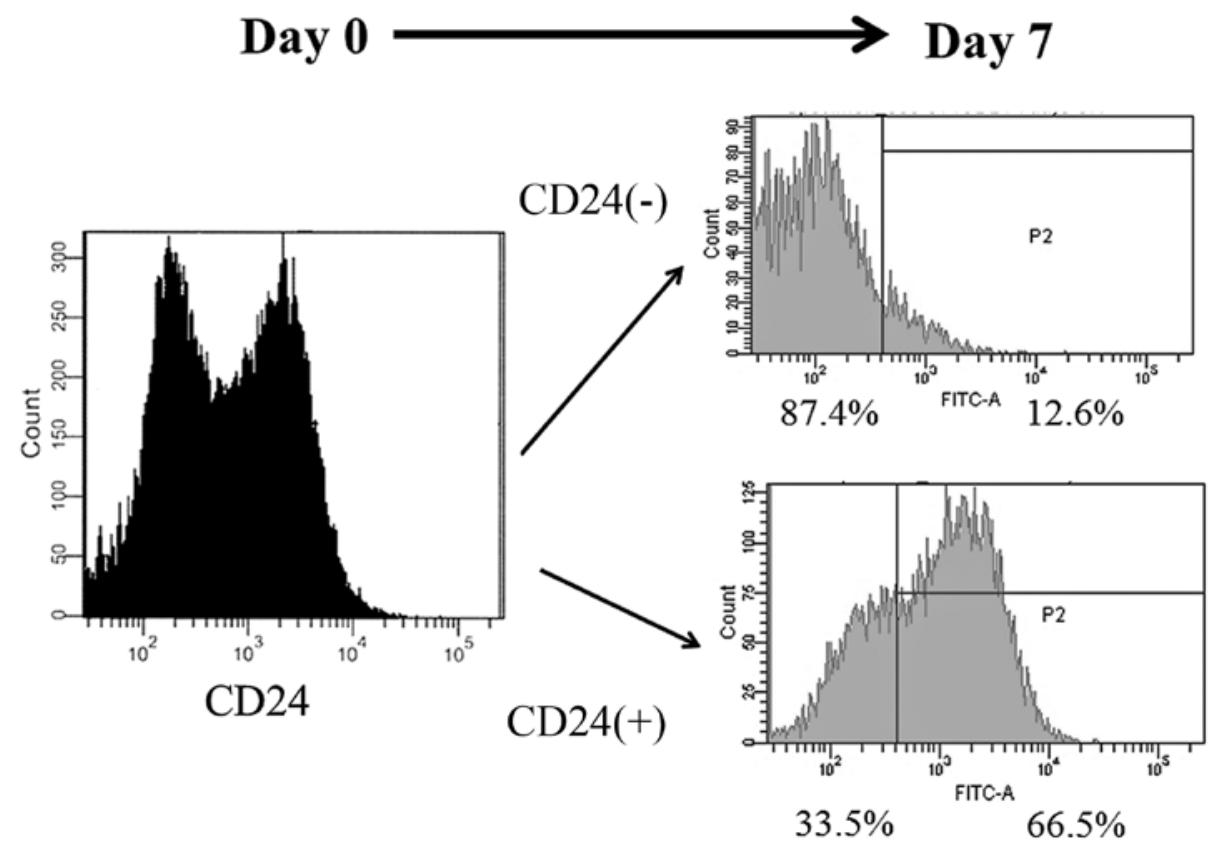

Figure 8. The long-term differentiation potential of CD24-positive cells. The CD24-positive or negative fractions of Caov-3 cells were evaluated in the fraction after 7 days of culture by flow cytometry. After 7 days of culture, 66.5\% of the CD24-positive fractions cells were CD24-positive and 33.5\% were CD24negative; $87.4 \%$ of the $\mathrm{CD} 24$-negative fractions cells were $\mathrm{CD} 24$-negative.

A

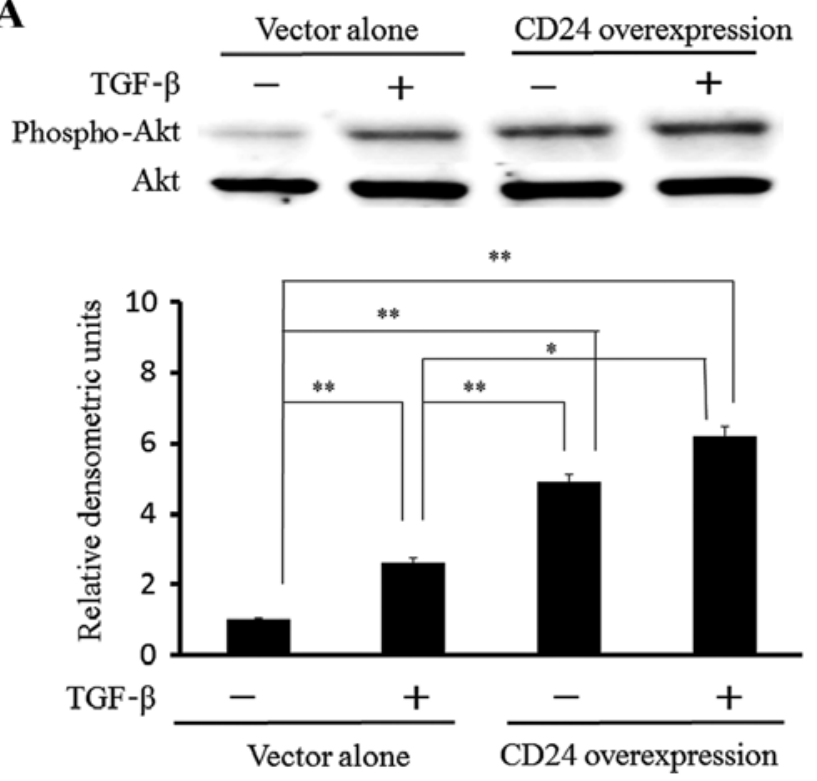

B
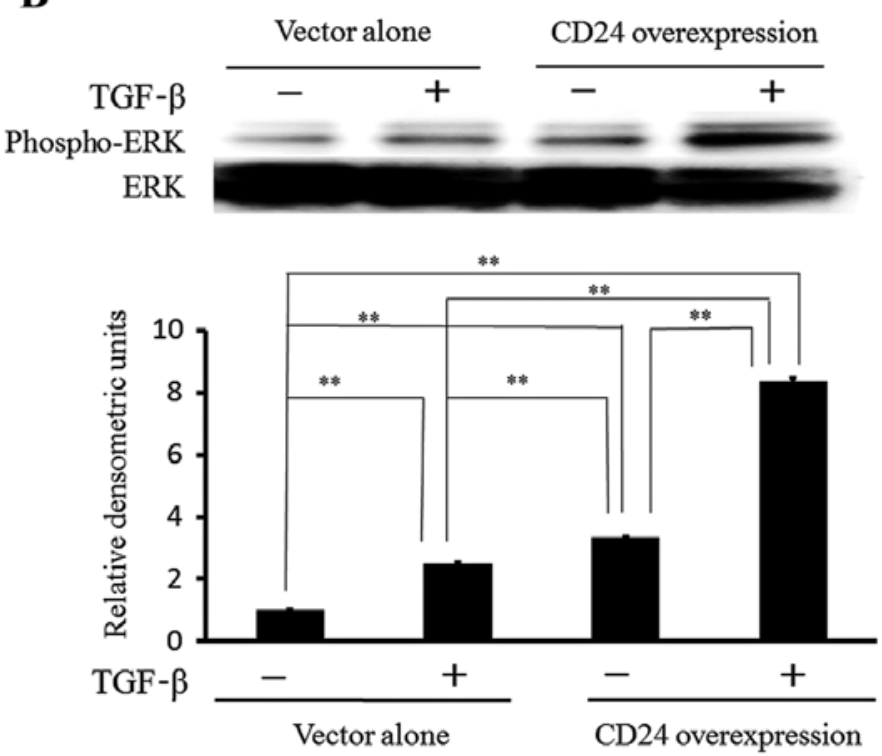

Figure 9. Western blotting reveals that CD24 enhances the TGF- $\beta$ induced phosphorylation of Akt and ERK in Caov-3 cells. Caov- 3 cells were treated in according to the procedure described in Materials and methods. After treatment with or without $10 \mathrm{ng} / \mathrm{ml}$ of TGF- $\beta$ for 10 min, cells lysates were subjected to SDS-page, and then western blotting was performed with an anti-phospho-Akt antibody or an anti-Akt antibody (A) and an anti-phospho-ERK antibody or an anti-ERK antibody (B). The values represent the means \pm SE from at least three independent experiments. ${ }^{*} \mathrm{p}<0.05 ;{ }^{* * *} \mathrm{p}<0.01$.

These data suggest that CD24 somehow enhances the TGF- $\beta$ signaling pathway and that the PI3K/Akt and MAPK pathways may be promoted via this enhanced TGF- $\beta$ signaling.

CD24 enhances the intra-abdominal disseminated tumorigenesis of ovarian cancer in vivo. Peritoneal dissemination is the primary route of progression in human ovarian cancer, and the amount of ascites and the disseminated tumor burden are correlated with the prognosis of human patients (34). We therefore examined the correlation between the expression of CD24 and the intra-abdominally disseminated tumorigenesis of ovarian cancer. We divided the Caov-3 cells into CD24-positive and CD24-negative fractions using MACS, and athymic nude mice were intraperitoneally inoculated with CD24-positive Caov-3 cells and CD24-negative cells, as described in Materials and methods. The appearance of the mice is shown in Fig. 10A. After 50 days, intra-abdominal dissemination was clearly detected in the athymic nude mice 

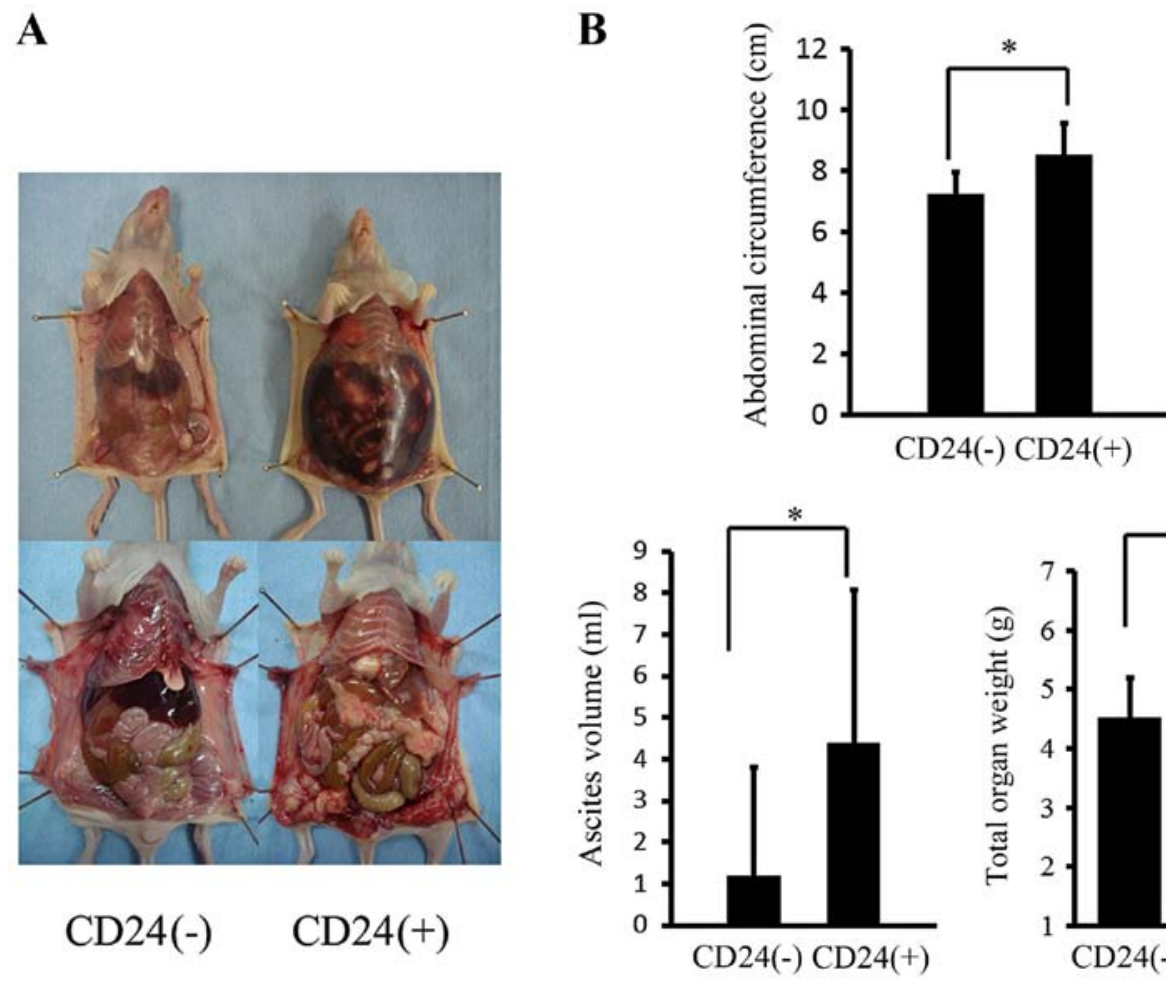

Figure 10. CD24-negative Caov-3 cells or CD24-positive Caov-3 cells were intra-abdominally injected into athymic nude mice. The body weight, abdominal circumference, and organ dissemination were determined at 50 days after the cell injection. (A) The physical appearance of the representative mice, and magnified views of the intra-abdominal dissemination pattern of the same mouse. (B) The body weight, abdominal circumference, and the total weight of the organs with dissemination and distant metastasis are shown for each group. ${ }^{*} \mathrm{p}<0.05$.

that were intraperitoneally inoculated with CD24-positive cells in comparison to CD24-negative cells. After performing a histological examination, the abdominal tumors were found to be papillary adenocarcinomas, which was consistent with the characteristics of the Caov-3 cells. The mean abdominal circumference after 50 days in the athymic nude mice that were intraperitoneally inoculated with CD24-positive cells was significantly higher than that observed in the mice with CD24-negative cells (Fig. 10B). The mean ascites volume after 50 days in the athymic nude mice that were intraperitoneally inoculated with CD-24 positive cells was also significantly higher than that observed in the mice with CD24-negative cells (Fig. 10B). The disseminated tumor weight after 50 days in the athymic nude mice that were intraperitoneally inoculated with CD24-positive cells was significantly higher than that in mice that were inoculated wit CD24-negative cells (Fig. 10B).

\section{Discussion}

We found that CD24 was expressed in $70.1 \%$ of ovarian cancers and that the expression of CD24 was an independent predictor of survival in patients with ovarian cancer. This finding is in line with previous reports $(35,36)$. Moreover, we demonstrated that the expression of CD24 was correlated with the FIGO stage $(\mathrm{p}<0.01)$, and the presence of peritoneal $(\mathrm{p}<0.01)$ and lymph node metastasis $(\mathrm{p}<0.01)$. In addition, CD24 induced the EMT phenomenon, which was involved in cell invasion, the highly proliferative phenotype, resistance to chemotherapy, and the properties of cancer stem-like cells (CSCs). Moreover, we clarified, for the first time, that the CD24-induced prolifera- tion and invasiveness in ovarian cancer were dependent on the activation of PI3K/Akt, NF- $\mathrm{B}$ and ERK.

EMT, which is associated with a key step in tumor metastasis via the induction of a highly invasive phenotype, has been intensely studied $(4,37)$. We previously showed that the expression of EMT-related proteins was correlated with the status of tumor metastasis or the prognostic value in ovarian carcinoma (38). Given that 33 of 174 patients $(19.0 \%)$ had EMT-positive status, as represented by both a reduced E-cadherin expression and the presence of nuclear Snail expression [4 (12.1\%) in the CD24-negative group and 29 (97.9\%) in the CD24-positive group], we concluded that a strong relationship existed between the expression of CD24 and EMT status $(\mathrm{p}<0.05)$ (data not shown). In this study, we demonstrated that CD24-positive ovarian cancer cells consistently acquired an EMT phenotype. These data indicate that CD24-positive cells are involved in the EMT process in ovarian cancer. In the present study, we also demonstrated that CD24-positive ovarian carcinomas have greater potential for intra-abdominal tumor cell dissemination and ascites production than CD24negative ovarian carcinomas in in vivo models.

EMT is a clinically important multifaceted pathological program that endows cancer cells with the ability of invasion, resistance to apoptosis and dissemination. EMT-inducing transcription factors such as Snail, Twist and Slug are aberrantly expressed in human cancers and are responsible for a poor prognosis in patients (5). In the present study, we demonstrated that CD24 enhanced the expression of Snail, and decreased the expression of E-cadherin in the Caov-3 cells. We herein demonstrated, for the first time, that CD24 amplified cell 
growth-related intracellular signaling via the PI3K/Akt and MAPK pathways by affecting the EMT signal pathways. Some groups have reported that EMT also contributes to the properties of CSCs $(31,32,39)$, and CSCs have been found to transiently acquire stem cell-like properties as a consequence of EMT (40). The CSC hypothesis states that solid tumors are hierarchically organized and sustained by a minority of the tumor cell population with stem cell-like properties, such as self-renewal, multilineage differentiation and tumorigenicity. CD24 is a mucin-like cell surface glycoprotein that is frequently overexpressed in various human cancers and is correlated with a poor prognosis $(35,41)$. Recent reports have revealed that CD24-positive cells function as CSCs in colon cancer, hepatocellular carcinoma, pancreatic carcinomas, and ovarian carcinomas $(23,24,41,42)$. In the present study, we also demonstrated that CD24-positive cells show self-renewal potential and cell differentiation potential after prolonged culture, and increase the colony-forming activity, invasive activity, proliferation activity, and resistance to cisplatin in comparison to CD24-negative cells. We also demonstrated that CD24 induced the EMT phenomenon, which was involved in cell invasion, resistance to chemotherapy, and the formation of side populations of CSCs (7); however, we could not clarify what regulated the expression of CD24, and CD24-positive cells were identical with ovarian cancer stem cells in that study. In the present study, we indicated that CD24 plays a critical role in regulating the EMT phenomenon in ovarian cancer. Our study provides novel insight into the interaction between CSCs and the EMT program and a better understanding of the mechanism underlying the involvement of CD24 in ovarian cancer metastasis. Given the findings in the present study, we believe that CD24 is a key molecule of metastatic progression in the EMT phenomenon and a promising therapeutic target for advanced ovarian cancer.

\section{Acknowledgements}

This study was supported by a JSPS KAKENHI grant no. 25462621 (to Y. Terai).

\section{References}

1. Ozols RF: Treatment goals in ovarian cancer. Int J Gynecol Cancer 15: 3-11, 2005.

2. Kalluri R and Weinberg RA: The basics of epithelial-mesenchymal transition. J Clin Invest 119: 1420-1428, 2009.

3. Kang Y and Massagué J: Epithelial-mesenchymal transitions: Twist in development and metastasis. Cell 118: 277-279, 2004.

4. Thiery JP: Epithelial-mesenchymal transitions in tumour progression. Nat Rev Cancer 2: 442-454, 2002.

5. Thiery JP, Acloque H, Huang RY and Nieto MA: Epithelialmesenchymal transitions in development and disease. Cell 139: 871-890, 2009.

6. Zeisberg $\mathrm{M}$ and Neilson EG: Biomarkers for epithelial-mesenchymal transitions. J Clin Invest 119: 1429-1437, 2009.

7. Krantz SB, Shields MA, Dangi-Garimella S, Munshi HG and Bentrem DJ: Contribution of epithelial-to-mesenchymal transition and cancer stem cells to pancreatic cancer progression. J Surg Res 173: 105-112, 2012.

8. Dalerba P, Cho RW and Clarke MF: Cancer stem cells: Models and concepts. Annu Rev Med 58: 267-284, 2007.

9. Kay R, Rosten PM and Humphries RK: CD24, a signal transducer modulating $\mathrm{B}$ cell activation responses, is a very short peptide with a glycosyl phosphatidylinositol membrane anchor. J Immunol 147: 1412-1416, 1991.
10. Aigner S, Ruppert M, Hubbe M, Sammar M, Sthoeger Z, Butcher EC, Vestweber D, Altevogt P and Kaufmann SHE: Heat stable antigen (mouse CD24) supports myeloid cell binding to endothelial and platelet P-selectin. Int Immunol 7: 1557-1565, 1995.

11. Lee KM, Ju JH, Jang K, Yang W, Yi JY, Noh DY and Shin I: $\mathrm{CD} 24$ regulates cell proliferation and transforming growth factor $\beta$-induced epithelial to mesenchymal transition through modulation of integrin $\beta 1$ stability. Cell Signal 24: 2132-2142, 2012.

12. Aigner S, Sthoeger ZM, Fogel M, Weber E, Zarn J, Ruppert M, Zeller Y, Vestweber D, Stahel R, Sammar M, et al: CD24, a mucin-type glycoprotein, is a ligand for P-selectin on human tumor cells. Blood 89: 3385-3395, 1997.

13. Sammar M, Aigner S and Altevogt P: Heat-stable antigen (mouse CD24) in the brain: Dual but distinct interaction with P-selectin and L1. Biochim Biophys Acta 1337: 287-294, 1997.

14. King JB, von Furstenberg RJ, Smith BJ, McNaughton KK, Galanko JA and Henning SJ: CD24 can be used to isolate Lgr $5^{+}$ putative colonic epithelial stem cells in mice. Am J Physiol Gastrointest Liver Physiol 303: G443-G452, 2012.

15. Deng J, Gao G, Wang L, Wang T, Yu J and Zhao Z: CD24 expression as a marker for predicting clinical outcome in human gliomas. J Biomed Biotechnol 2012: 517172, 2012.

16. Shi Y, Gong HL, Zhou L, Tian J and Wang Y: CD24: A novel cancer biomarker in laryngeal squamous cell carcinoma. ORL J Otorhinolaryngol Relat Spec 74: 78-85, 2012.

17. Kristiansen G, Schlüns K, Yongwei Y, Denkert C, Dietel M and Petersen I: CD24 is an independent prognostic marker of survival in nonsmall cell lung cancer patients. Br J Cancer 88: 231-236, 2003.

18. Kristiansen G, Winzer KJ, Mayordomo E, Bellach J, Schlüns K, Denkert C, Dahl E, Pilarsky C, Altevogt P, Guski H, et al: CD24 expression is a new prognostic marker in breast cancer. Clin Cancer Res 9: 4906-4913, 2003.

19. Lee HJ, Kim DI, Kwak C, Ku JH and Moon KC: Expression of $\mathrm{CD} 24$ in clear cell renal cell carcinoma and its prognostic significance. Urology 72: 603-607, 2008.

20. Su N, Peng L, Xia B, Zhao Y, Xu A, Wang J, Wang X and Jiang B: Lyn is involved in CD24-induced ERK1/2 activation in colorectal cancer. Mol Cancer 11: 43, 2012.

21. Liu C, Zheng S, Shen H, Xu K, Chen J, Li H, Xu Y, Xu A, Chen B, Kaku H, et al: Clinical significance of CD24 as a predictor of bladder cancer recurrence. Oncol Lett 6: 96-100, 2013.

22. Zhu J, Zhang G and Lu H: CD24, COX-2, and p53 in epithelial ovarian cancer and its clinical significance. Front Biosci (Elite Ed) 4: 2745-2751, 2012.

23. Li C, Heidt DG, Dalerba P, Burant CF, Zhang L, Adsay V, Wicha M, Clarke MF and Simeone DM: Identification of pancreatic cancer stem cells. Cancer Res 67: 1030-1037, 2007.

24. Gao MQ, Choi YP, Kang S, Youn JH and Cho NH: CD24+ cells from hierarchically organized ovarian cancer are enriched in cancer stem cells. Oncogene 29: 2672-2680, 2010.

25. Kim KH, Choi JS, Kim JM, Choi YL, Shin YK, Lee HC, Seong IO, Kim BK, Chae SW and Kim SH: Enhanced CD24 expression in endometrial carcinoma and its expression pattern in normal and hyperplastic endometrium. Histol Histopathol 24: 309-316, 2009.

26. Taylor MA, Parvani JG and Schiemann WP: The pathophysiology of epithelial-mesenchymal transition induced by transforming growth factor-beta in normal and malignant mammary epithelial cells. J Mammary Gland Biol Neoplasia 15: 169-190, 2010.

27. Zavadil J and Böttinger EP: TGF-beta and epithelial-to-mesenchymal transitions. Oncogene 24: 5764-5774, 2005.

28. Lee YH, Albig AR, Regner M, Schiemann BJ and Schiemann WP: Fibulin-5 initiates epithelial-mesenchymal transition (EMT) and enhances EMT induced by TGF-beta in mammary epithelial cells via a MMP-dependent mechanism. Carcinogenesis 29: 2243-2251, 2008.

29. Miettinen PJ, Ebner R, Lopez AR and Derynck R: TGF-beta induced transdifferentiation of mammary epithelial cells to mesenchymal cells: Involvement of type I receptors. J Cell Biol 127: 2021-2036, 1994.

30. Jiang J, Tang YL and Liang XH: EMT: A new vision of hypoxia promoting cancer progression. Cancer Biol Ther 11: 714-723, 2011.

31. Bao B, Wang Z, Ali S, Kong D, Banerjee S, Ahmad A, Li Y, Azmi AS, Miele L and Sarkar FH: Over-expression of FoxM1 leads to epithelial-mesenchymal transition and cancer stem cell phenotype in pancreatic cancer cells. J Cell Biochem 112: 2296-2306, 2011. 
32. Mani SA, Guo W, Liao MJ, Eaton EN, Ayyanan A, Zhou AY, Brooks M, Reinhard F, Zhang CC, Shipitsin M, et al: The epithelial-mesenchymal transition generates cells with properties of stem cells. Cell 133: 704-715, 2008

33. Reya T, Morrison SJ, Clarke MF and Weissman IL: Stem cells, cancer, and cancer stem cells. Nature 414: 105-111, 2001.

34. Roszkowski P, Wronkowski Z, Szamborski J and Romejko M: Evaluation of selected prognostic factors in ovarian cancer. Eur J Gynaecol Oncol 14 (Suppl): 140-145, 1993.

35. Kristiansen G, Denkert C, Schlüns K, Dahl E, Pilarsky C and Hauptmann S: CD24 is expressed in ovarian cancer and is a new independent prognostic marker of patient survival. Am J Pathol 161: 1215-1221, 2002

36. Surowiak P, Materna V, Kaplenko I, Spaczynski M, Dietel M, Kristiansen G, Lage $\mathrm{H}$ and Zabel $\mathrm{M}$ : Unfavorable prognostic value of CD24 expression in sections from primary and relapsed ovarian cancer tissue. Int J Gynecol Cancer 16: 515-521, 2006.

37. Grünert S, Jechlinger $M$ and Beug $H$ : Diverse cellular and molecular mechanisms contribute to epithelial plasticity and metastasis. Nat Rev Mol Cell Biol 4: 657-665, 2003.

38. Takai M, Terai Y, Kawaguchi H, Ashihara K, Fujiwara S, Tanaka T, Tsunetoh S, Tanaka Y, Sasaki H, Kanemura M, et al: The EMT (epithelial-mesenchymal-transition)-related protein expression indicates the metastatic status and prognosis in patients with ovarian cancer. J Ovarian Res 7: 76, 2014.
39. Hollier BG, Tinnirello AA, Werden SJ, Evans KW, Taube JH, Sarkar TR, Sphyris N, Shariati M, Kumar SV, Battula VL, et al: FOXC2 expression links epithelial-mesenchymal transition and stem cell properties in breast cancer. Cancer Res 73: 1981-1992, 2013.

40. Iwatsuki M, Mimori K, Yokobori T, Ishi H, Beppu T, Nakamori S, Baba $\mathrm{H}$ and Mori M: Epithelial-mesenchymal transition in cancer development and its clinical significance. Cancer Sci 101: 293-299, 2010

41. Lee TK, Castilho A, Cheung VC, Tang KH, Ma S and Ng IO CD24(+) liver tumor-initiating cells drive self-renewal and tumor initiation through STAT3-mediated NANOG regulation. Cell Stem Cell 9: 50-63, 2011.

42. Yeung TM, Gandhi SC, Wilding JL, Muschel R and Bodmer WF: Cancer stem cells from colorectal cancer-derived cell lines. Proc Natl Acad Sci USA 107: 3722-3727, 2010. 